\title{
DESCONCENTRAÇÃO REGIONAL DA INDÚSTRIA NO BRASIL: RAZÕES PARA COMEMORAR?*
}

\author{
Recebido: 15 de junho de 2018 • Aprovado: 19 de setembro de 2018 \\ https://doi.org/10.22395/seec.v22n50a7
}

Aristides Monteiro Neto**

Raphael De Oliveira Silva ${ }^{* * *}$

\section{RESUMO}

O artigo analisa a desconcentração da indústria e seus rebatimentos no território nacional entre 1996 e 2015, utiliza um conjunto de indicadores, tais como valor de transformação industrial, produtividade da indústria e índice de Theil de desigualdade para cinco grupos de indústrias, definidos segundo o fator competitivo predominante. Conclui-se pela continuidade do movimento de desconcentração regional de atividades industriais. Contudo, sublinha que há também razões para se preocupar: uma é que a desconcentração ocorre em ambiente de perda de relevância da atividade industrial e outra é que a desconcentração se verifica de modo mais significativo em ramos intensivos em recursos naturais e em trabalho, setores tradicionais com baixa capacidade de produção e difusão de progresso técnico.

\section{PALAVRAS-CHAVE}

Atividade econômica regional; distribuição da atividade econômica regional; estrutura industrial; Brasil.

\section{CLASSIFICAÇÃO JEL}

L10, O14, R11, R12

\section{CONTEÚDO}

Introdução; 1. Desenvolvimento regional concentrado no Brasil: aspectos do debate; 2. A dinâmica setorial da indústria no período 1996-2015; 3. Distribuição regional do VTI em contexto de regressão industrial; 4. Conclusões; Bibliografia.

- O presente estudo é produto do projeto de investigação Desconcentração Territorial e Reestruturação Regressiva da Indústria: o padrão brasileiro recente (1995-2015), realizado no Instituto de Pesquisa Economia Aplicada (Ipea) no período de janeiro de 2017 a maio de 2018.

“ Economista, Universidade Federal de Pernambuco, Recife, Brasil. Mestre em Teoria Econômica, Universidade Federal de Pernambuco. Doutor em Economia Aplicada, Universidade Estadual de Campinas (Unicamp), Campinas, Brasil. Pesquisador sênior do Instituto de Pesquisa Economia Aplicada (Ipea) ligado ao Ministério do Planejamento do governo federal, Brasília, Brasil. E-mail: aristides.monteiro@ipea.gov.br

*** Economista, Universidade Federal Fluminense, Rio de Janeiro, Brasil. Mestre em Economia Aplicada Universidade Federal de São Carlos (UFSCar), Sorocaba, Brasil. Pesquisador associado do Instituto de Pesquisa Economia Aplicada, Brasília, Brasil. E-mail: raphael.silva@ipea.gov.br 


\title{
DESCONCENTRACIÓN REGIONAL DE LA INDUSTRIA EN BRASIL: ¿RAZONES PARA CONMEMORAR?
}

\section{RESUMEN}

El artículo analiza la desconcentración de la industria y sus efectos en el territorio nacional entre 1996 y 2015. Para ello, utiliza un conjunto de indicadores, tales como valor de transformación industrial, productividad de la industria e índice de Theil de desigualdad para cinco grupos de industrias, definidos según el factor competitivo predominante. Se concluye por la continuidad del movimiento de desconcentración regional de actividades industriales. Sin embargo, se destaca que también hay razones para preocuparse: una es que la desconcentración ocurre en ambiente de pérdida de relevancia de la actividad industrial y otra es que la desconcentración se verifica de manera más significativa en sectores intensivos en recursos naturales y en trabajo, áreas tradicionalmente con baja capacidad de producción y difusión de progreso técnico.

\section{PALABRAS CLAVE}

Actividad económica regional; distribución de la actividad económica regional; estructura industrial; Brasil.

\section{CLASSIFICACIÓN JEL}

\section{L10, O14, R11, R12}

\section{CONTENIDO}

Introducción; 1. Desarrollo regional concentrado en Brasil: aspectos del debate; 2. La dinámica sectorial de la industria en el periodo 1996-2015; 3. Distribución regional del VTI en contexto de regresión industrial; 4. Conclusiones; Bibliografía.

\section{REGIONAL DECONCENTRATION OF INDUSTRY IN BRAZIL: REASONS TO CELEBRATE?}

\begin{abstract}
The article analyzes the deconcentration of the industry and its implications in the national territory between 1996 and 2015 and uses a set of indicators, such as rate of industrial transformation (RIT), industry productivity and Theil index of inequality for five industry groups, defined according to the principal competitive factor. It concludes by the continuity of the regional deconcentration movement of industrial activities. However, it stresses that there are also reasons to be concerned: one is that the deconcentration occurs in an environment of loss of relevance of industrial activity and another is that the deconcentration is more significant in the intensive branches of natural resources and work, traditional sectors with low production capacity and dissemination of technical progress.
\end{abstract}

\section{KEYWORDS}

Regional economic activity; distribution of regional economic activity; industrial structure; Brazil.

\section{JEL CLASSIFICATION}

L10, O14, R11, R12

\section{CONTENT}

Introduction 1. Regional development concentrated in Brazil: aspects of the debate; 2. Industrial sector dynamics in the 1996-2015 period; 3. Regional distribution of the RIT in the context of industrial regression; 4. Conclusions; Bibliography. 


\section{INTRODUÇÃO}

O artigo discute o processo de desconcentração das atividades industriais no território brasileiro do período entre 1996-2015. Registra que um leque de preocupações, apontadas por vários estudiosos, tais como, Cano (1998), Pacheco (1998) e Negri (1996), inicialmente, em meados dos anos 1990, relacionado à possibilidade de reconcentração produtiva no território, de enfraquecimento dos laços econômicos entre as regiões e de desindustrialização da economia brasileira, fenômenos decorrentes das reformas liberais de abertura comercial, financeira e privatizações da economia brasileira realizadas por governos liberais entre 1990 e 2002, tornou-se o centro do debate regional desde então.

Com o intuito de atualizar e avançar no debate, o presente estudo utiliza um conjunto de indicadores formado pelo valor de transformação industrial, produtividade da indústria e índice de Theil de desigualdade, classificados segundo o fator competitivo predominante da atividade industrial.

As evidências obtidas confirmam que a reconcentração produtiva não se concretizou. Entretanto, o enfraquecimento da atividade industrial se estabeleceu, caracterizado por baixas taxas de crescimento, sua persistente dificuldade em elevar os níveis de produtividade média do trabalho e sua re-especialização em ramos industriais relacionados à base de recursos naturais. O estudo conclui, por fim, a existência de um padrão regressivo da indústria que se instalou na região mais desenvolvida e se espalhou regionalmente, e manteve as características de heterogeneidade estrutural. A desconcentração territorial de atividades em vez de produzir mudanças estruturais nas regiões recebedores de atividades industriais apenas reforçam padrões pretéritos de crescimento.

O artigo se organiza, além desta introdução, em três seções estruturais e uma conclusão final. Na seção 2, são especificados os aspectos centrais do debate atual sobre o enfraquecimento da indústria e seus rebatimentos na dinâmica de desconcentração regional. Na seção 3, são discutidos elementos da dinâmica da indústria brasileira com vistas a demonstração de que houve desconcentração territorial, mas, diferentemente do período anterior — quando a desconcentração articulava a indústria de São Paulo, o centro dinâmico da economia nacional, com as economias regionais por meio de elos intersetoriais de impulso e, por isso, foi chamada de desconcentração virtuosa - , a partir de meados dos anos 1990, o processo de desindustrialização consubstanciou-se em quebra de elos das economias regionais ao mercado nacional e caracterizou uma trajetória de desconcentração do tipo espúria. 


\section{DESENVOLVIMENTO REGIONAL CONCENTRADO NO BRASIL: ASPECTOS DO DEBATE}

O Brasil se caracterizou, no século XX, por elevadas taxas de crescimento econômico associadas a um intenso processo de industrialização e urbanização. Um dos resultados indesejados dessa etapa de transformações estruturais foi a elevada concentração territorial das atividades econômicas. A economia da região Sudeste, composta pelos estados de São Paulo, Rio de Janeiro, Minas Gerais e Espírito Santo, transformou-se na mais importante do país já desde fins do século XIX, com o boom da demanda internacional sobre a economia cafeeira e permanece assim desde então. Segundo estatísticas de contas nacionais (Instituto Nacional de Geografia e Estadística — $\mathrm{IBGE})^{1}$, a região Sudeste foi responsável, em 1949, por 65,9 \% do Produto Interno Bruto (PIB) nacional, que atingiu 62,4 \% em 1980 e ainda mantém seu protagonismo com 54,0\% do total no ano de 2015.

Há uma tendência à desconcentração regional da atividade econômica, mais visivelmente depois de 1970, mas esta ocorre em velocidade muito reduzida. Conforme apontado pelo Grupo de Trabalho para o Desenvolvimento do Nordeste — GTDN (1967), Programa Integrado de Mestrado em Economia e Sociologia— Pimes (1984) e Cano (1998), por conta das dificuldades para produzir uma orientação firme para o melhor uso das possibilidades contidas no enorme território nacional, a questão regional tem sido, desde fins dos anos 1950, um tema muito relevante do debate político e acadêmico nacional.

Uma das vertentes do debate aponta a grande relevância do papel da indústria como fator dinâmico da expansão de atividades econômicas e, portanto, como vetor de forças de concentração e desconcentração a cada momento. Se no período 1930-1970, de intensa industrialização, a tônica foi a concentração industrial na região Sudeste com epicentro em São Paulo, a partir de 1970 observou-se um fenômeno de desconcentração em direção à região Sul e, mais fracamente, para as regiões Nordeste e Norte. Tomou forma e avançou pela primeira vez em mais de um século de transformações da sua economia um processo de convergência do produto per capita estadual e regional no Brasil. A indústria de transformação em São Paulo respondia por 48,9 \% do total nacional do setor em 1949 e por 58,1 \% em 1970. Em 2015, esse percentual foi reduzido para 37,9\% do total nacional, mas ainda representa a parcela mais importante da indústria brasileira.

O IBGE é o órgão oficial do governo brasileiro, ligado ao Ministério do Planejamento, para realização das contas econômicas nacionais e regionais, bem como dos dados censos populacionais. 
De um lado, as crescentes deseconomias de aglomeração² na região metropolitana de São Paulo, e também no restante do estado, contribuíram para a busca de novos territórios e mão de obra mais barata para a indústria e, de outro lado, a ação do governo federal - por meio de políticas regionais de desenvolvimento, da criação de infraestruturas de comunicações e energia visando a integração do mercado nacional e de elevados investimentos das empresas de propriedade estatal — foi decisiva para o estímulo à localização de empreendimentos privados em áreas estagnadas ou mais pobres do país, conforme indica Cano (1998).

Contudo já em fins dos anos 1980, com a crise fiscal e financeira que se abateu sobre a economia brasileira, a capacidade de atuação do Estado foi bastante comprometida e isso o impediu de continuar a realizar as inversões necessárias para a redução das disparidades regionais. O processo de desconcentração passou a enfraquecer-se e a preocupação com a reconcentração de atividade produtiva voltou à agenda nacional. Cano (1998), Pacheco (1998), Negri (1996), Diniz (1995) e Diniz e Crocco (1996) foram alguns dos estudiosos que começaram a alertar que o novo ambiente de abertura comercial e financeira da economia brasileira, se não fosse devidamente monitorado, poderia levar ao enfraquecimento, por meio de um nível de concorrência externa exacerbada, da indústria nacional. Nesse cenário adverso à indústria, a atividade econômica tenderia a reconcentrar-se na região Sudeste onde o nível instalado de infraestruturas e de qualificação da mão de obra eram muito superiores.

Após a década de 1990, com a constatação da perda de relevância da atividade industrial no país, isto é, da desindustrialização, as preocupações ficaram ainda mais intensas. A sinalização de perda de substância industrial da economia brasileira indica uma desindustrialização precoce — em fase de renda média ainda baixa para os padrões internacionais-, que tenderá a produzir limitações intransponíveis para o crescimento futuro, inclusive das atividades terciárias e que terá repercussões danosas sobre o desenvolvimento regional equilibrado no país (Cano, 2012; Arend, Singh e Bicharra, 2016).

Dado o reconhecimento de que a atividade industrial teve historicamente um papel determinante para a integração das economias regionais ao mercado nacional por meio de diversos mecanismos intersetoriais de articulação, os quais foram benéficos para o crescimento nas regiões menos desenvolvidas, é feito um esforço de avaliação das consequências do seu enfraquecimento e redução de seu tamanho

2 As deseconomias de aglomeração correspondem a aumentos de custos de produção associados à concentração excessiva de atividades numa dada localidade. Quando ocorrem, tendem a anular os benefícios gerados nas aglomerações e gerar externalidades negativas como o aumento de congestionamentos, poluição, escassez de terrenos e mão de obra, e isso resulta na elevação de custos operacionais. 
para a dinâmica do desenvolvimento regional brasileiro. Existe uma preocupação em identificar se há ou não processo de desconcentração regional, mas busca-se avaliar em quais setores, a partir das especializações industriais, a desconcentração tomou entre 1996 e 2015.

\section{A DINÂMICA SETORIAL DA INDÚSTRIA NO PERÍODO 1996-2015}

\subsection{Base de dados e classificação de atividades industriais}

A investigação da trajetória e transformações da indústria é feita com base na série de dados do valor da transformação industrial (VTI) para ramos da indústria extrativa, de transformação e indústria total para o período 1996-2015 segundo a Pesquisa Industrial Anual (PIA) do IBGE ${ }^{3}$. Os dados são deflacionados para valores em R\$ de 2015, segundo o Índice do Produtor Amplo (IPA) da Fundação Getúlio Vargas (FGV).

A classificação da Organization for Economic Cooperation and Development - OECD (1987) com base no fator competitivo predominante na indústria é utilizada para identificar grupos de indústria nas regiões brasileiras. Para esse fim, os ramos industriais foram reagrupados segundo cinco tipos de fatores de competitividade, a saber: i) indústrias cujo principal fator competitivo interno são os recursos naturais; ii) indústrias intensivas em mão de obra e, portanto, cujo diferencial competitivo é o fator trabalho; iii) indústrias intensivas em escala de produção e que se apoiam em redução de custos por meio de expansão de rendimentos de escala; iv) indústrias com tecnologia diferenciada que lhes permite atender, em escala considerável, a diversificados tipos de demanda a partir de uma mesma linha de produção, e e) indústrias baseadas em ciência em que seu diferencial competitivo é tipo avançado, específico e singular de tecnologia incorporada no produto que lhe permite obter, durante um período de tempo razoável, rendas do monopólio da invenção. ${ }^{4}$

A classificação permite avaliar se a produção e a comercialização de produtos intensivos em mão de obra e/ou em recursos naturais apresentam forte proximidade com as dotações de fatores identificadas em regiões menos desenvolvidas

\footnotetext{
No período analisado houve mudança da CNAE 1.0 para a 2.0, portanto, foi realizada uma compatibilização entre as séries com a retirada de setores da CNAE 1.0 que não estavam presentes na CNAE 2.0 e vice-versa. São enquadradas nessa exclusão as atividades de Reciclagem da CNAE 1.0 e as atividades de Manutenção de Equipamentos da CNAE 2.0.

4 Sobre a metodologia ver OCDE (1987) e aplicações práticas para a União Europeia em Borbély (2004) e para o Brasil em Nassif (2008). Os ramos de atividade que compõem cada grupo de indústria são os seguintes, segundo a classificação brasileira oficial CNAE 2.0 do IBGE: a) intensivos em recursos naturais —extração de: carvão mineral; petróleo e serviços relacionados; minerais metálicos; minerais não metálicos; fabricação de: produtos alimentícios e bebidas; produtos de fumo; produtos de madeira; celulose, papel e produtos de papel; coque, refino de petróleo, elaboração de combustíveis nucleares e produção de álcool; e produtos minerais não metálicos; b) intensivos em mão de obra - fabricação de: produtos têxteis; artigos de vestuário e acessórios; preparação de couros e fabricação de artefatos de couro, artigos de viagem e calçados; produtos de metal (exceto máquinas e equipamentos); móveis e industrias diversas; reciclagem; c) indústrias baseadas em
} 
dentro do país. Alternativamente, lança luz sobre as especializações regionais em produtos intensivos em escala - por serem resultantes de processos prolongados de redução de custos (nas firmas) tendem a ser mais intensas nas regiões onde o desenvolvimento industrial teve início mais favorável, o que causou dificuldades para outra região competir na mesma produção. Do mesmo modo, a especialização regional em bens diferenciados, assim como nos produtos baseados em ciência, por causa dos elevados custos fixos e riscos em Pesquisa e Desenvolvimento (PED), frequentemente promove obstáculos intransponíveis para novas regiões entrantes. Por essas razões, a tipologia permite evidenciar se, no caso brasileiro, o processo de concentração regional de economias de aglomeração nas atividades industriais mostra sinais de reversão.

\subsection{Trajetória da atividade industrial no período}

A forma sob a qual a restruturação da atividade industrial se apresentou no período investigado tem um caráter regressivo predominante. Para Galeano e Feijó (2013), esse fenômeno tem sido associado à redução da produtividade média do trabalho nessas atividades. Para efeitos da presente discussão, a regressividade é definida pela atuação conjunta de três fatores: a) baixo crescimento de seu VTI, b) redução da produtividade média por trabalhador e c) perda de densidade industrial pelo aumento de importância das atividades intensivas em recursos naturais e em trabalho. Cada uma dessas facetas será discutida a seguir.

Sobre o ritmo de crescimento da indústria. Os dados analisados mostram que o ajustamento da indústria brasileira se caracterizou por uma trajetória de baixas taxas anuais de crescimento da atividade manufatureira (Tabela 1). A indústria total apresenta evolução lenta e seus grupos produtivos (extrativa e transformação) têm movimentos divergentes. A extrativa apresenta expansão muito forte de seu VTI à taxa anual de 9,4 \% entre 1996-2015, com sua aceleração maior entre 1996-2006 do que na fase posterior. A indústria de transformação mostra variação bem inferior à taxa de 1,6 \% ao ano (a.a.) e crescimento mais acelerado depois de 2007. A performance acelerada da indústria extrativa pouco conseguiu alterar a trajetória de crescimento do VTI da indústria total; aqui o peso muito menos preponderante dos ramos de extrativa — ainda que na presença de taxas muito elevadas de expansão— na indústria total pouco repercutiu sobre a expansão global da indústria.

escala - edição, impressão e reprodução de gravações; fabricação de produtos químicos e farmacêuticos; artigos de borracha e plástico; metalurgia básica; fabricação e montagem de veículos automotores, reboques e carrocerias; d) indústrias de tecnologias diferenciadas — fabricação de: máquinas e equipamentos; máquinas, aparelhos e materiais elétricos; e e) indústrias baseadas em ciência - fabricação de: equipamentos de informática, produtos eletrônicos e ópticos; outros equipamentos de transporte, exceto veículos automotores; manutenção, reparação e instalação de máquinas e equipamentos. 
Classificadas as indústrias por fator competitivo, nota-se também como nos grupos em que a indústria manufatureira brasileira está consolidada, ela apresentou fraca evolução do seu VTI. Os intensivos em trabalho e em escala quase estagnados no período com taxas, respectivas, de 0,8 \% e 0,4 \% a.a., além do grupo de indústrias com tecnologias diferenciadas com variação negativa para o período total. As indústrias intensivas em recursos naturais experimentaram destaque favorável por suas taxas elevadas e seu peso no conjunto da indústria. As atividades baseadas em ciência aparecem também com forte aceleração, contudo, partem de uma base comparativa pequena e estão em fase de consolidação de suas atividades.

O quadro revelado é de preocupação quanto ao perfil setorial que a indústria vem constituindo no país. A restruturação da indústria brasileira combina fraca evolução dos ramos de atividade mais relevantes (baseados em trabalho, em escala e diferenciados) com expansão significativa das atividades baseadas em recursos naturais.

Tabela 1. Evolução do Valor da Transformação Industrial (VTI) e da Produtividade Média do Trabalho (VTI/POC), por tipo de Indústria e Fator Competitivo

\begin{tabular}{|c|c|c|c|c|c|c|c|c|c|}
\hline & \multicolumn{4}{|c|}{$\begin{array}{c}\text { Taxas (\%) de Crescimento Anuais do } \\
\text { VTI }\end{array}$} & \multicolumn{5}{|c|}{$\begin{array}{c}\text { Evolução da Produtividade Média do } \\
\text { Trabalho (VTI/POC) } \\
\text { Número-índice }(1996=100)\end{array}$} \\
\hline & $\begin{array}{l}1996 / \\
2015\end{array}$ & & $\begin{array}{l}1996 / \\
2006\end{array}$ & $\begin{array}{c}2007 / \\
2015\end{array}$ & 1996 & 2000 & 2005 & 2010 & 2015 \\
\hline Total & 1,81 & & 1,66 & 1,93 & 100 & 107 & 90 & 94 & 98 \\
\hline Extrativa & 14,50 & & 4,31 & 9,38 & 100 & 187 & 238 & 300 & 256 \\
\hline Transformação & 1,23 & & 1,43 & 1,55 & 100 & 104 & 85 & 86 & 90 \\
\hline \multicolumn{10}{|c|}{ Grupo de Indústria por Fator Competitivo } \\
\hline Recursos naturais & 4,29 & 3,22 & & 3,81 & 100 & 126 & 119 & 135 & 135 \\
\hline Trabalho & $-1,16$ & 1,81 & & 0,80 & 100 & 89 & 69 & 78 & 83 \\
\hline Escala & 0,82 & $-0,70$ & & 0,40 & 100 & 102 & 88 & 85 & 84 \\
\hline Diferenciada & $-1,07$ & 1,13 & & $-1,26$ & 100 & 92 & 70 & 66 & 67 \\
\hline Baseada em ciência & 4,81 & 1,73 & & 6,59 & 100 & 141 & 77 & 71 & 78 \\
\hline
\end{tabular}

Fonte: elaboração própria com base nos dados brutos de Valor da Transformação Industrial (VTI) e população ocupada (POC), Pesquisa Anual da Indústria (PIA-IBGE). Deflator utilizado: IPA-FGV (2015=100).

Sobre a produtividade da indústria. Em processo de modernização produtiva e de mudança estrutural espera-se que as atividades industriais sejam portadoras 
da elevação da produtividade geral da economia. No entanto, no Brasil, entre 1996 e 2015, isso aconteceu com pouca intensidade. A produtividade média do trabalho na indústria, estimada pela relação entre o VTI e o número de pessoas ocupadas na atividade (VTI/POC), apresentou características divergentes do padrão esperado. A produtividade média da indústria total se expande de 1996 até início dos anos 2000; em seguida, a trajetória de redução se instala e permanece. Em 2015, o nível de produtividade (98) encontrou-se abaixo do observado 20 anos antes em 1996 (Tabela 1).

Foi na indústria de transformação que o nível médio de produtividade do trabalho se tornou mais problemático. Atingiu o nível mais alto também até início dos anos 2000, em seguida passou a declinar. Em 2005, atingiu o valor de 85,0, o mais baixo da série acima, para em seguida realizar uma retomada para o nível de 90 em 2015. Apresentou-se em 2015 com o nível de 90 \% do VTI/POC realizado em 1996.

Noutro compasso expandiu-se aceleradamente a produtividade média da atividade extrativa, cujo nível do período 2010-2015 é três vezes o seu valor inicial em 1996. Os dados revelam a diferença nas trajetórias da indústria extrativa e de transformação, além de apontar que o comportamento excepcional da extrativa não foi capaz de induzir a expansão da produtividade no restante das atividades industriais de transformação.

Sobre a especialização setorial. A estrutura industrial brasileira perdeu densidade técnica no período. As atividades da indústria de transformação, na qual a produção e a difusão do progresso técnico costumam ser mais relevantes e gerar ganhos de escala e redução de custo médio maiores, sofreram um encolhimento considerável. Sua participação no total do VTI do setor foi de 97,7 \% em 2006 e foi reduzida ao final do período para 90,7 \% (Tabela 2).

Ao aproveitar o contexto favorável para a exportação de commodities agrominerais, a pauta industrial teve como grande beneficiada a atividade extrativa, cuja participação no VTI da indústria foi praticamente triplicada no período. Essa faceta de especialização de parte da atividade industrial é mais bem compreendida pela análise do grupo de indústria definido pelo fator competitivo.

Fica mais evidente a forte especialização em atividades ligadas a recursos naturais, as quais passaram de cerca de 1/3 em 2006 na composição do VTI para, praticamente, $50 \%$ do conjunto das atividades industriais em 2015. Tornou-se, o grupo de indústrias intensivas em recursos naturais, aquele com atividade predominante na pauta industrial brasileira. Perdem terreno na composição setorial da 
indústria as atividades intensivas em trabalho (de 14,4\% para 11,5\%) e as intensivas em escala (de $35,5 \%$ para $26,2 \%$ ) que tinham significativa presença nas atividades e chegaram, conjuntamente, a deter 49,9\% do total em 1996; findaram em 2015 com apenas $37,7 \%$. Também as atividades de tecnologia diferenciadas — representativas de robustez tecnológica e de elevada competitividade — não foram poupadas; houve redução de metade de sua posição relativa (de 13,4 \% para 7,1 \%). Experimentou uma expansão o grupo de baseadas em ciência, que passou de 2,3 \% para 5,7 \% entre o início e o final do período.

Tabela 2. Composição Relativa (\%) do Valor da Transformação Industrial (VTI), por tipo de Indústria e Fator Competitivo

\begin{tabular}{lccccc}
\hline \multirow{2}{*}{ Tipo de Indústria } & \multicolumn{5}{c}{ Participação (\%) } \\
\cline { 2 - 6 } & 1996 & 2000 & 2005 & 2010 & 2015 \\
\hline Total & 100 & 100 & 100 & 100 & 100 \\
\hline Extrativa & 2,3 & 5,4 & 8,6 & 11,0 & 9,2 \\
\hline Transformação & 97,7 & 94,6 & 91,4 & 89,0 & 90,7 \\
\hline & Grupo de Indústria por Fator Competitivo & & \\
\hline Recursos Naturais & 34,5 & 39,7 & 44,2 & 46,5 & 49,5 \\
\hline Trabalho & 14,4 & 12,2 & 10,6 & 11,8 & 11,5 \\
\hline Escala & 35,5 & 33,5 & 32,6 & 29,0 & 26,2 \\
\hline Diferenciada & 13,4 & 11,0 & 9,6 & 7,5 & 7,1 \\
\hline Baseada em ciência & 2,3 & 3,7 & 3,0 & 5,2 & 5,7 \\
\hline
\end{tabular}

Fonte: elaboração própria com base nos dados brutos de Valor da Transformação Industrial (VTI) e população ocupada (POC), Pesquisa Anual da Indústria (PIA-IBGE). Deflator utilizado: IPA-FGV (2015=100).

As informações indicam a prevalência de um cenário da indústria brasileira de ajustamento produtivo com fortes características regressivas. A produtividade da indústria de transformação, em particular, foi reduzida e somente os ramos de indústria ligados aos setores intensivos em recursos naturais apresentaram ganhos de produtividade média. Por fim, a composição do VTI entre grupos de indústria se redefiniu no sentido contrário do que se espera para países que buscam consolidar sua estrutura produtiva, ou seja, em vez de aumentar a diversificação setorial, o país viu sua indústria se tornar mais dependente e concentrada em ramos ligados a atividades baseadas em recursos naturais ( $49,5 \%$ do total). 


\section{DISTRIBUIÇÃO REGIONAL DO VTI EM CONTEXTO DE REGRESSÃO INDUSTRIAL}

\subsection{Distribuição regional: padrão e ritmo}

Nesta seção usa-se o índice de Theil, que consiste numa medida estatística de distribuição. Por meio dele, busca-se uma visão da trajetória de disparidades no VTI da indústria no período 1996-2015. Essa medida de distribuição é conhecida na literatura, além de ser discutida e utilizada, entre outros, por Bourguignon (1979) e Ram (1992). O índice utilizado segue a seguinte especificação:

$$
\mathrm{L}=\sum p_{i}{ }^{*} \ln \left(\frac{p_{i}}{v t i_{i}}\right)
$$

Onde $\mathrm{p}_{\mathrm{i}}$ e vti $\mathrm{i}_{\mathrm{i}}$ são, respectivamente, as participações do estado (ou região) $i$ no total da população $\left(\mathrm{P}_{\mathrm{i}} / \mathrm{P}_{\mathrm{n}}\right)$ e no total do $\mathrm{vti}_{\mathrm{i}}\left(\mathrm{VTI}_{\mathrm{i}} / \mathrm{VTI}_{\mathrm{n}}\right)$ nacional; ln é o logaritmo natural. Essa medida de desigualdade não assume valores negativos e sua distribuição torna-se igualitária quando $\mathrm{L}=0$, isto é, quando a participação da população de cada estado (região) $i$ e sua respectiva participação no VTI são iguais. O limite inferior do índice é zero e seu limite superior não é 1. Quando o índice atinge a unidade ou superior, a desigualdade é considerada alta. Esse índice independe de variações de tamanho entre estados (regiões). A entropia capta todos os momentos da distribuição enquanto as demais medidas comumente usadas, tais como o coeficiente de variação, baseiam-se apenas na média e na dispersão.

O coeficiente L de Theil é calculado para o VTI da indústria total, extrativa e transformação nos recortes interestadual e inter-regional. Dados para as desigualdades foram calculados para todos os anos do período 1996-2015, mas para efeitos de economia de espaço são apresentados apenas os dados para três anos escolhidos (Tabela 3). Contudo, a trajetória inteira das desigualdades para o VTI da indústria total está representada no Gráfico 1. Ela é mais reduzida em nível no recorte inter-regional do que no interestadual, ou seja, as diferenciações são mais evidentes entre as economias estaduais (em maior número) do que nas regionais (em menor número). Configuraram-se dois momentos mais evidentes: um de ascensão até 2006-2008, seguido por uma fase de queda.

$\mathrm{Na}$ indústria como um todo, as disparidades interestaduais inicialmente aumentaram e depois caíram e, como saldo, o valor final foi $27 \%$ superior ao do ano inicial. No recorte inter-regional, há queda no nível da desigualdade com o valor final estabelecido abaixo ( $28 \%$ menor) do valor inicial. Foram calculadas taxas anuais de crescimento dos índices para o período total de 1996-2015 e subperíodos de 
1996-2005 e 2006-20155. Regra geral, as desigualdades em ambos os recortes interestadual e inter-regional apresentaram tendência de expansão no primeiro subperíodo e de queda no seguinte.

Gráfico 1. Índice de Theil para desigualdade interestadual e inter-regional do VTI na Indústria Total, 1996-2015

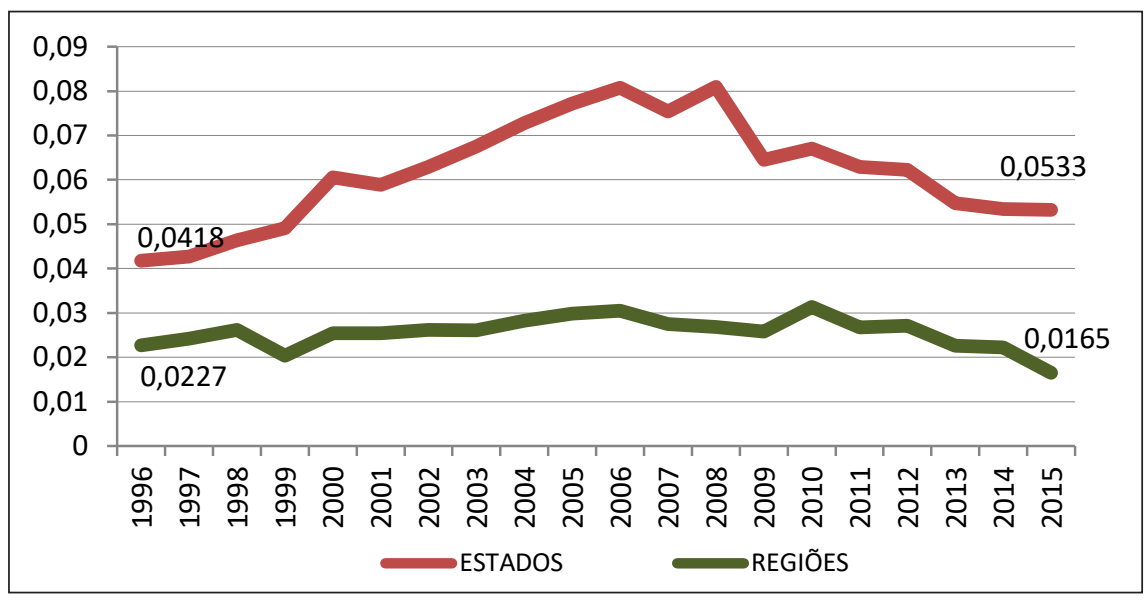

Fonte: elaboração própria com base nos dados brutos de Valor da Transformação Industrial (VTI) e população ocupada (POC), Pesquisa Anual da Indústria (PIA-IBGE). Deflator utilizado: IPA-FGV (2015=100).

$\mathrm{Na}$ indústria total, desigualdades interestaduais crescem a uma taxa de 7,2 \% a.a. entre 1996-2006 e decrescem no subperíodo seguinte à taxa de $-4,9 \%$ a.a. O saldo geral do período 1996-2015 é, contudo, um aumento das disparidades à taxa de $1,3 \%$ a.a. As desigualdades inter-regionais apresentam comportamento mais suave do que as mesmas desigualdades entre as economias estaduais com aumento à taxa de $2,8 \%$ no primeiro subperíodo e desaceleração de $-4,9 \%$ a.a. no subperíodo seguinte, de tal sorte que, no período total, houve uma redução à taxa de $-0,3$ \% a.a.

A atividade extrativa apresentou, em todos os subperíodos, taxas positivas de crescimento das desigualdades de Theil, uma vez que na primeira fase de 1996-2005 o aumento das disparidades foi mais intenso do que no subperíodo seguinte. Ora no recorte interestadual ora no inter-regional, as atividades extrativas contribuíram para a expansão das disparidades totais. O que não é incomum, uma vez que as atividades de extração de petróleo e minerais são muito concentradas em poucas partes do território nacional. Esse setor de atividade apresentou crescimento elevado de 3,6 \% a.a. na desigualdade do VTI segundo o referido índice.

\footnotetext{
$5 \quad$ As taxas de crescimento são obtidas por ajustamento de uma função exponencial; por esse procedimento as taxas obtidas expressam a informação de todos os dados da série e não apenas de seus pontos inicial e final.
} 
Tabela 3. Índice de Theil para o VTI, Valor Absoluto e Taxas (\%) anuais de crescimento*

\begin{tabular}{|c|c|c|c|}
\hline & Indústria Total & Extrativa & Transformação \\
\hline \multicolumn{4}{|c|}{ Interestadual — Índice de Desigualdade de Theil } \\
\hline 1996 & 0,0418 & 0,1432 & 0,0448 \\
\hline 2006 & 0,0807 & 0,3202 & 0,0687 \\
\hline 2015 & 0,0533 & 0,3340 & 0,0368 \\
\hline \multicolumn{4}{|c|}{ Inter-regional -Índice de Desigualdade de Theil } \\
\hline 1996 & 0,0227 & 0,0738 & 0,0222 \\
\hline 2006 & 0,0305 & 0,1861 & 0,0221 \\
\hline 2015 & 0,0165 & 0,1442 & 0,0104 \\
\hline \multicolumn{4}{|c|}{ Interestadual — Taxa de variação do índice } \\
\hline $1996 / 2015$ & 1,3 & 3,5 & $-1,5$ \\
\hline 1996/2006 & 7,2 & 9,0 & 4,2 \\
\hline $2007 / 2015$ & $-4,9$ & $-0,6$ & $-8,5$ \\
\hline \multicolumn{4}{|c|}{ Inter-regional — Taxa de variação do índice } \\
\hline $1996 / 2015$ & $-0,3$ & 3,6 & $-3,9$ \\
\hline 1996/2006 & 2,8 & 9,4 & $-0,4$ \\
\hline $2007 / 2015$ & $-4,9$ & 1,1 & $-9,1$ \\
\hline
\end{tabular}

Nota: * Taxas de crescimento obtidas por ajustamento de função exponencial para toda a série de índices de $\mathrm{n}=20$.

Fonte: dados brutos da Pesquisa Anual da Indústria (PIA) e População/Censos Demográficos, do IBGE.

Na indústria de transformação, o índice de desigualdades apresentou evolução descendente (taxas negativas) em quase todos os períodos analisados. Na verdade, são as atividades de transformação que concorrem mais fortemente para que as disparidades totais sejam reduzidas. No recorte interestadual, sua evolução foi de $-1,5 \%$ a.a. nas duas décadas entre 1996-2015 anualmente, enquanto no recorte inter-regional a queda foi mais intensa, de $-3,9 \%$ a.a.

\subsection{Ganhos/perdas na composição regional da atividade industrial}

Embora o coeficiente de Theil apresentado na seção anterior constate uma redução na trajetória geral da disparidade interestadual e inter-regional na indústria, ele não permite a observação dos padrões regionais/estaduais específicos, isto é, não evidencia quem ganha e quem perde participação na atividade produtiva. São mostradas as participações de cada estado/região no ano inicial e final e o saldo 
da relação ganho/perda, o que permite uma outra leitura do processo de desconcentração em curso (Tabela 4).

O espraiamento do VTI parte da região Sudeste e, particularmente, da economia de São Paulo para o restante do país. A economia desse estado perde 15,3 pontos percentuais (p.p.) no período considerado, que são distribuídos em parte para os demais estados da própria região - o Rio de Janeiro expande 2,6 p.p., o Espírito Santo ganha 1,4 p.p. e Minas Gerais adiciona 0,7 p.p., no total esses três aumentaram sua participação em 4,7 p.p.

As economias estaduais da região Sul avançaram 5,0 p.p. no VTI da indústria nacional. Os avanços foram mais representativos, respectivamente, para o Paraná (+2,0 p.p.), Santa Catarina ( $+1,8$ p.p.) e Rio Grande do Sul $(+1,2$ p.p.). Essa região isoladamente teve aumento de sua participação equivalente a $46,7 \%$ da perda ocorrida na região Sudeste. A atividade extrativa teve papel de pouca importância e sua produção foi reduzida de 4,5\% para 2,4 \% entre 1996 e 2015. É na indústria de transformação que os estados da região se destacaram com ganhos de 6,2 p.p. (de 16,2 \% em 1996 para 22,4 \% em 2015) no total nacional.

Na direção do Centro-Oeste, houve expansão da indústria total com ganhos de 3,1 p.p., com destaque para Goiás, Mato Grosso e Mato Grosso do Sul com índices, respectivamente, de 1,6, 0,9 e 0,6 p.p. cada. Esse vetor de desconcentração foi capaz de capturar o equivalente a 30,8\% da parte desconcentrada pelo Sudeste. O vigor de sua produção industrial esteve nas atividades de transformação em que os ganhos totais foram de 3,5 p.p. no período. A indústria extrativa regional teve participação no total nacional reduzida de 3,6 \% em 1996 para 2,3 \% em 2015.

A região Nordeste constitui-se em terceiro destino das forças de desconcentração da indústria. Teve sua participação na indústria total aumentada em 2,2 p.p. (de $8,6 \%$ para 10,8 \%) e a economia estadual com maior destaque foi a da Bahia com ganhos de 1,2 p.p. Todas as demais economias estaduais tiveram incrementos pouco significativos com exceção de Alagoas que teve, na verdade, redução de participação ( $-0,5$ p.p.). A indústria extrativa regional recuou e perdeu 7,7 p.p. no total nacional da extrativa, com quedas mais acentuadas no Rio Grande do Norte (-3,6 p.p.) e na Bahia (-3,8 p.p.). Na direção contrária, a indústria de transformação ganhou 2,7 p.p. no período. Novamente, o destaque foi para a Bahia que aumentou 1,4 p.p. no total nacional.

Na região Norte, o movimento da indústria foi fraco. O ganho regional no total da indústria foi de apenas 0,3 p.p. A indústria de transformação regional teve papel relevante para o resultado geral, pois seu ganho de 1,2 p.p. no total nacional contrabalançou a perda regional de 16,8 p.p. na extrativa nacional. 
Tabela 4. Regiões e Estados. Composição (\%) Regional do Valor da Transformação Industrial (VTI), para a Indústria Total, Extrativa e Transformação

\begin{tabular}{|c|c|c|c|c|c|c|c|c|c|}
\hline \multirow{2}{*}{$\begin{array}{c}\text { Grandes Regiões e Unidades - } \\
\text { da Federação }\end{array}$} & \multicolumn{3}{|c|}{ Indústria Total } & \multicolumn{2}{|c|}{ Indústria Extrativa } & \multicolumn{4}{|c|}{ Indústria de Transformação } \\
\hline & 1996 & 2015 & $\begin{array}{l}\text { Ganhol } \\
\text { Perda }\end{array}$ & 1996 & 2015 & $\begin{array}{l}\text { Ganhol } \\
\text { Perda }\end{array}$ & 1996 & 2015 & $\begin{array}{c}\text { Ganhol } \\
\text { Perda }\end{array}$ \\
\hline Norte & 4,0 & 4,3 & 0,3 & 17,0 & 0,2 & $-16,8$ & 3,4 & 4,6 & 1,2 \\
\hline $\mathrm{RO}$ & 0,1 & 0,3 & 0,2 & 0,1 & 0,0 & $-0,1$ & 0,1 & 0,3 & 0,2 \\
\hline$A C$ & 0,0 & 0,0 & 0,0 & 0,0 & 0,0 & 0,0 & 0,0 & 0,0 & 0,0 \\
\hline AM & 2,4 & 2,9 & 0,5 & 0,0 & 0,0 & 0,0 & 2,5 & 3,2 & 0,7 \\
\hline RR & 0,0 & 0,0 & 0,0 & 0,0 & 0,0 & 0,0 & 0,0 & 0,0 & 0,0 \\
\hline PA & 1,3 & 0,9 & $-0,4$ & 15,3 & 0,1 & $-15,2$ & 0,8 & 1,0 & 0,2 \\
\hline AP & 0,1 & 0,0 & $-0,1$ & 1,5 & 0,0 & $-1,5$ & 0,0 & 0,0 & 0,0 \\
\hline TO & 0,0 & 0,1 & 0,1 & 0,0 & 0,0 & 0,0 & 0,0 & 0,1 & 0,1 \\
\hline Nordeste & 8,6 & 10,8 & 2,2 & 16,4 & 8,7 & $-7,7$ & 8,2 & 10,9 & 2,7 \\
\hline MA & 0,4 & 0,7 & 0,3 & 0,1 & 0,1 & 0,0 & 0,4 & 0,7 & 0,3 \\
\hline PI & 0,1 & 0,2 & 0,1 & 0,0 & 0,0 & 0,0 & 0,1 & 0,2 & 0,1 \\
\hline CE & 1,0 & 1,5 & 0,5 & 0,2 & 0,2 & 0,0 & 1,1 & 1,6 & 0,5 \\
\hline RN & 0,5 & 0,7 & 0,2 & 6,7 & 3,1 & $-3,6$ & 0,3 & 0,5 & 0,2 \\
\hline $\mathrm{PB}$ & 0,4 & 0,4 & 0,1 & 0,0 & 0,0 & 0,0 & 0,4 & 0,5 & 0,1 \\
\hline $\mathrm{PE}$ & 1,7 & 1,9 & 0,2 & 0,0 & 0,1 & 0,1 & 1,8 & 2,0 & 0,3 \\
\hline $\mathrm{AL}$ & 0,9 & 0,4 & $-0,5$ & 0,1 & 0,0 & $-0,1$ & 0,9 & 0,5 & $-0,5$ \\
\hline SE & 0,2 & 0,4 & 0,2 & 2,3 & 1,6 & $-0,5$ & 0,2 & 0,3 & 0,1 \\
\hline $\mathrm{BA}$ & 3,3 & 4,5 & 1,2 & 7,0 & 3,2 & $-3,8$ & 3,2 & 4,6 & 1,4 \\
\hline Centro-Oeste & 2,6 & 5,8 & 3,2 & 3,6 & 2,3 & $-1,2$ & 2,6 & 6,1 & 3,5 \\
\hline MS & 0,5 & 1,0 & 0,6 & 1,1 & 0,2 & $-0,9$ & 0,4 & 1,1 & 0,7 \\
\hline MT & 0,6 & 1,5 & 0,9 & 0,2 & 0,3 & 0,1 & 0,6 & 1,6 & 1,0 \\
\hline $\mathrm{GO}$ & 1,3 & 2,9 & 1,6 & 2,2 & 1,8 & $-0,4$ & 1,2 & 3,0 & 1,8 \\
\hline DF & 0,2 & 0,3 & 0,1 & 0,1 & 0,0 & $-0,1$ & 0,2 & 0,3 & 0,1 \\
\hline $\mathrm{NO}+\mathrm{NE}+\mathrm{CO}$ & 15,1 & 20,8 & 5,7 & 37,0 & 11,2 & $-25,8$ & 14,2 & 21,7 & 7,4 \\
\hline Sudeste & 69,2 & 58,5 & $-10,7$ & 68,6 & 86,4 & 27,9 & 69,6 & 55,9 & $-13,7$ \\
\hline MG & 9,9 & 10,6 & 0,7 & 38,2 & 23,2 & $-15,0$ & 8,7 & 9,5 & 0,7 \\
\hline ES & 1,6 & 3,0 & 1,4 & 11,2 & 18,1 & 6,9 & 1,2 & 1,6 & 0,4 \\
\hline RJ & 7,4 & 10,0 & 2,6 & 2,1 & 43,2 & 41,1 & 7,7 & 6,9 & $-0,7$ \\
\hline $\mathrm{SP}$ & 50,2 & 34,9 & $-15,3$ & 7,1 & 2,0 & $-5,1$ & 52,0 & 37,9 & $-14,1$ \\
\hline Sul & 15,7 & 20,7 & 5,0 & 4,5 & 2,4 & $-2,1$ & 16,2 & 22,4 & 6,2 \\
\hline PR & 5,3 & 7,3 & 2,0 & 1,2 & 0,6 & $-0,5$ & 5,5 & 7,9 & 2,4 \\
\hline SC & 3,9 & 5,7 & 1,8 & 1,3 & 1,1 & $-0,2$ & 4,0 & 6,1 & 2,1 \\
\hline RS & 6,5 & 7,7 & 1,2 & 2,0 & 0,6 & $-1,4$ & 6,7 & 8,4 & 1,7 \\
\hline SE + SUL & 84,9 & 79,2 & $-5,7$ & 63,0 & 88,8 & 25,8 & 85,8 & 78,3 & $-7,4$ \\
\hline
\end{tabular}

Fonte: elaboração própria com base nos dados brutos de Valor da transformação Industrial (VTI) da Pesquisa Anual da Indústria (PIA-IBGE). Deflator utilizado: IPA-FGV (2015=100). 
Numa leitura conclusiva, nota-se que o sentido da desconcentração regional da atividade industrial continua se espraiando da economia paulista em direção às economias estaduais da região Sudeste (exceto SP) e do Sul. Adicionalmente, as atividades chegam às economias das três demais regiões: Norte, Nordeste e Centro - Oeste. O território relevante para a localização da atividade industrial continua a se constituir no Sudeste e Sul, que ainda detêm, em 2015, 79,2 \% do VTI da indústria total e 78,3 \% da indústria de transformação.

\subsection{Especializações regionais}

A divisão inter-regional da indústria consolidada até a década de 1980 alocou para a região mais dinâmica industrialmente os ramos de maior densidade de capital e tecnológica. Mesmo na década de 1990, conforme apontam estudos, a divisão regional do trabalho manteve-se com o predomínio de atividades mais intensivas em capital e tecnologia e de maior produtividade no Sudeste-Sul e, com variações, as atividades de menor intensidade de capital e inferior produtividade média nas regiões menos desenvolvidas (Cano, 1998).

Para o período 1996-2015, esse padrão esperado de articulação inter-regional é analisado. O objetivo é obter elementos que indiquem o tipo de especialização produtiva regional prevalecente e o padrão de produtividade média associado.

Medidas de localização espacial estão bastante disseminadas na literatura apropriada e o coeficiente de especialização (CE) territorial é um dos mais conhecidos. Sua estimativa visa à observação do padrão setorial constatado nas regiões brasileiras ao longo desse ajustamento regressivo da indústria. O coeficiente CE é dado pela seguinte razão:

$$
\mathrm{CE}=\frac{\left(\frac{\mathrm{VTI}_{r}^{i}}{\operatorname{VTI}_{r}^{t}}\right)}{\left(\frac{\operatorname{VTI}_{b r}^{i}}{\operatorname{VTI}_{b r}^{t}}\right)}
$$

onde $\mathrm{VTI}_{r}{ }^{i}$ é o VTI do grupo de indústrias $i$ na região $r ; \mathrm{VTI}_{r}{ }_{r}$ é o VTI do total da indústria $t$ na região $r$; $\operatorname{VTI}_{b r}{ }^{i}$ é oVTI do grupo de indústrias $i$ no país $b r ; \operatorname{VTI}_{b r}{ }^{t}$ é oVTI do total da indústria $t$ no país $6 r$. Quando $C E<1$, a região $r$ é menos especializada no setor $i$ que o país; se $C E=1$, a região tem o mesmo patamar de especialização que o país como um todo; e se $\mathrm{CE}>1$, então, a região é mais especializada no setor $i$ que o país como um todo, conforme Haddad et al. (1989). 
Dados sobre a especialização produtiva são apresentados na Tabela 5, segundo a disponibilidade de fator competitivo verificada na indústria em cada grande região brasileira. Os ramos de indústria intensivos em recursos naturais são relativamente mais importantes na estrutura industrial regional no Centro-Oeste, no Norte e no Nordeste em que o coeficiente de especialização (CE) é maior do que a unidade, isto é, esses ramos apresentam posição relativa superior, numa dada região, à posição dos mesmos ramos no conjunto do país.

No Centro-Oeste, o VTI dos ramos baseados em recursos naturais tem valor absoluto acima do das regiões Norte e Nordeste, ou seja, indica que essa região é mais relevante para a geração de valor agregado. Esse é um comportamento compatível com seu perfil produtivo atual baseado em processamento de exportáveis de soja, milho e do complexo de carnes.

Na região Sudeste, a mais desenvolvida do país, o grupo de indústrias baseadas em recursos naturais é importante vetor de especialização regional. Esse resultado está em consonância com a expansão das atividades de extração e refino de petróleo e derivados no litoral do Rio de Janeiro e do Espírito Santo, com a produção de álcool de cana-de-açúcar no interior de São Paulo e com a extração e o processamento de minério de ferro em Minas Gerais.

Quanto às indústrias intensivas em trabalho, o coeficiente de especialização para o VTI é mais intenso e superior à unidade (CE $>1)$, nesta ordem, nas regiões Sul e Nordeste; para essas regiões, os ramos de indústria do grupo são proporcionalmente mais relevantes na estrutura industrial do que no total nacional, o que indica a relevância do fator mão de obra como recurso competitivo mais favorável. Nas demais partes do país, o coeficiente de especialização produtiva revelou-se inferior à unidade.

O grupo que reúne os ramos de indústria com fator competitivo preponderante intensivo em escala está concentrado em maior intensidade na região Sudeste com coeficiente superior à unidade ( $C E=1,18$ em 1996 e $C E=1,14$ em 2015). É em atividades com perfil de fator tecnológico avançado com predomínio de empresas multinacionais consolidadas que esta região tem mais destaque. A participação regional desse grupo de atividades no total nacional é muito elevada e chegou a $67,5 \%$ em 2015. Depois do Sudeste, esses ramos são também relevantes na estrutura produtiva do Nordeste e do Sul do país, com CE próximo da unidade em 2015, e um pouco menos relevantes nas regiões Norte e Centro-Oeste. 
Aristides Monteiro Neto y Raphael De Oliveira Silva

Tabela 5. Regiões e Estados. Indicadores de Especialização, de Produtividade (VTI/POC) e de Participação (\%) regional do VTI, segundo o Fator Competitivo

\begin{tabular}{|c|c|c|c|c|c|c|c|c|c|}
\hline \multirow[t]{2}{*}{$\begin{array}{l}\text { Grupo de Indústria por } \\
\text { Fator Competitivo }\end{array}$} & \multicolumn{3}{|c|}{$\begin{array}{c}\text { Coeficiente de Especiali- } \\
\text { zação do VTI }\end{array}$} & \multicolumn{3}{|c|}{$\begin{array}{l}\text { Razão Região vs. País } \\
\text { da Produtividade Média }\end{array}$} & \multicolumn{3}{|c|}{$\begin{array}{c}\text { Participação (\%) da Região no } \\
\text { Total Nacional do VTI do Grupo } \\
\text { de Indústria }\end{array}$} \\
\hline & 1996 & 2005 & 2015 & 1996 & 2005 & 2015 & 1996 & 2005 & 2015 \\
\hline \multicolumn{10}{|c|}{ Baseado em Recursos Naturais } \\
\hline Norte & 1,08 & 1,02 & 0,83 & 1,20 & 1,09 & 0,82 & 4,9 & 5,3 & 3,5 \\
\hline Nordeste & 1,36 & 1,19 & 1,14 & 0,62 & 0,64 & 0,73 & 10,4 & 11,1 & 12,1 \\
\hline Sudeste & 0,87 & 0,94 & 0,96 & 1,23 & 1,35 & 1,28 & 59,6 & 60,1 & 57,0 \\
\hline Sul & 1,17 & 0,98 & 0,93 & 0,82 & 0,69 & 0,76 & 20,2 & 17,4 & 18,9 \\
\hline Centro-Oeste & 2,17 & 1,71 & 1,51 & 0,83 & 0,75 & 0,87 & 4,9 & 6,1 & 8,5 \\
\hline \multicolumn{10}{|c|}{ Intensivo em Mão de Obra } \\
\hline Norte & 0,45 & 0,53 & 0,84 & 3,11 & 2,37 & 2,62 & 2,0 & 2,8 & 3,5 \\
\hline Nordeste & 1,08 & 1,22 & 1,26 & 0,86 & 0,83 & 0,84 & 8,3 & 11,4 & 13,4 \\
\hline Sudeste & 0,88 & 0,83 & 0,80 & 1,03 & 1,06 & 1,00 & 60,0 & 53,3 & 47,0 \\
\hline Sul & 1,65 & 1,67 & 1,58 & 0,97 & 0,94 & 1,01 & 28,5 & 29,9 & 32,4 \\
\hline Centro-Oeste & 0,52 & 0,74 & 0,67 & 0,54 & 0,89 & 0,98 & 1,2 & 2,7 & 3,8 \\
\hline \multicolumn{10}{|c|}{ Intensivo em Escala } \\
\hline Norte & 0,36 & 0,49 & 0,61 & 1,07 & 1,09 & 1,32 & 1,7 & 2,6 & 2,6 \\
\hline Nordeste & 0,92 & 0,89 & 0,91 & 1,13 & 1,21 & 1,11 & 7,0 & 8,3 & 9,7 \\
\hline Sudeste & 1,18 & 1,15 & 1,14 & 1,05 & 1,06 & 1,03 & 80,7 & 73,6 & 67,5 \\
\hline Sul & 0,56 & 0,78 & 0,84 & 0,72 & 0,75 & 0,85 & 9,7 & 13,8 & 17,1 \\
\hline Centro-Oeste & 0,45 & 0,47 & 0,55 & 0,56 & 0,57 & 0,81 & 1,0 & 1,7 & 3,1 \\
\hline \multicolumn{10}{|c|}{ Diferenciado } \\
\hline Norte & 2,47 & 2,26 & 0,57 & 2,39 & 2,11 & 0,93 & 11,0 & 11,9 & 2,4 \\
\hline Nordeste & 0,33 & 0,37 & 0,48 & 0,71 & 0,67 & 0,88 & 2,6 & 3,4 & 4,3 \\
\hline Sudeste & 0,98 & 0,97 & 1,07 & 0,94 & 0,97 & 1,05 & 66,9 & 61,2 & 60,9 \\
\hline Sul & 1,12 & 1,25 & 1,34 & 0,93 & 0,92 & 0,93 & 19,4 & 23,0 & 30,5 \\
\hline Centro-Oeste & 0,08 & 0,13 & 0,37 & 0,49 & 0,47 & 0,95 & 0,2 & 0,4 & 1,9 \\
\hline \multicolumn{10}{|c|}{ Baseado em Ciência } \\
\hline Norte & 5,75 & 4,36 & 6,99 & 2,13 & 1,47 & 1,57 & 22,0 & 19,4 & 21,3 \\
\hline Nordeste & 0,23 & 0,78 & 0,31 & 0,43 & 1,30 & 0,77 & 1,8 & 6,2 & 4,8 \\
\hline Sudeste & 0,99 & 0,98 & 0,95 & 0,89 & 0,92 & 0,96 & 66,7 & 65,0 & 60,8 \\
\hline Sul & 0,24 & 0,41 & 0,54 & 0,62 & 0,73 & 0,61 & 9,0 & 9,1 & 12,1 \\
\hline Centro-Oeste & 0,32 & 0,05 & 0,04 & 0,50 & 0,20 & 0,54 & 0,5 & 0,3 & 1,0 \\
\hline
\end{tabular}

Fonte: elaboração própria com base nos dados brutos de Valor da transformação Industrial (VTI) da Pesquisa Anual da Indústria (PIA-IBGE). Deflator utilizado: IPA-FGV $(2015=100)$. 
Nos ramos de intensidade tecnológica diferenciada, apresentam relevância vis-à-vis ao padrão nacional do grupo mais acentuada nas regiões Sul e Sudeste do que nas demais.

Por fim, as indústrias baseadas em conhecimento são mais relevantes para as regiões Norte e Sudeste em que os coeficientes de especialização são mais elevados. O elevado valor do coeficiente para a região Norte somente é explicado pela importância da produção de 21,8 \% do total nacional do grupo em 1996 e 20,6 \% em 2015, atraídos pelos incentivos financeiros e fiscais oferecidos pela Zona Franca de Manaus (ZFM) no estado do Amazonas. A elevada concentração desses ramos de indústria em Manaus se deve aos volumosos incentivos fiscais dados para sua localização nessa região e não se refere necessariamente ao esforço de elevação da densidade tecnológica regional.

No Sudeste registra-se a parcela de $66,7 \%$ do VTI desse grupo de tecnologia baseada em ciência no país em 1996, com leve queda para 60,8 \% em 2015. O estado de São Paulo foi responsável por 51 \% do total nacional do grupo em 1996; em 2015, esse patamar ficou em 41,3 \%. Depois do Sudeste é na região Sul que essas atividades estão mais especializadas com a participação regional no total nacional que atingiu 9,0 \% em 1996 e cresceu para 12,0 \% em 2015.

O exame dos níveis de produtividade dos grupos de indústria ressalta aspectos relevantes das especializações regionais. As regiões mais especializadas $(C>1)$ em indústrias baseadas em recursos naturais — Norte, Nordeste e Centro-Oesteapresentam nível de produtividade do grupo de indústria abaixo da média nacional do mesmo grupo. Na região Nordeste, a produtividade desse grupo é a mais baixa entre todas as regiões brasileiras: em 1996, correspondia a 62 \% e, em 2015, a 73 \% do patamar nacional em cada ano. A produtividade na região Norte apresentou um padrão de queda no período, mas seu nível médio era bastante elevado e acima do nacional até, pelo menos, 2015.

Do mesmo modo, no grupo de intensivas em trabalho, a produtividade média na região Sudeste é superior à média nacional e superior a todas as demais regiões (exceto a região Norte). No Nordeste, que apresenta um padrão elevado de especialização em atividades intensivas em trabalho, a produtividade dessas atividades, embora crescente no período, é inferior ao padrão médio nacional (em 2015, correspondia a $84 \%$ da média nacional). Na região Norte, a produtividade média é bem mais elevada — mais de duas vezes - do que a média nacional e contrasta com o observado nas demais regiões. Concorrem para esse resultado as 
especializações da Zona Franca de Manaus em fabricação de produtos metálicos e de produtos diversos ${ }^{6}$.

Nas atividades intensivas em escala ocorre situação inversa à esperada. Nas regiões Norte e Nordeste, cujas especializações nas atividades são inferiores à média nacional, a produtividade média setorial ficou acima do padrão nacional e superior até mesmo do observado na região Sudeste. Esse comportamento pode significar que o esforço de modernização produtiva induzido por políticas federais e estaduais, de fato, está estimulando nessas regiões a localização de plantas industriais mais eficientes e produtivas. Na região Centro-Oeste, verifica-se baixa tradição em ramos da indústria intensiva em escala e também sua menor, em termos nacionais, produtividade média. Contudo, há um esforço de expansão desses tipos de atividade (e seu CE cresce no período) e, em simultâneo, os ramos instalados têm elevado sua produtividade de maneira significativa: correspondia a 56 \% do nacional em 1996 e já estão em 81 \% em 2015. Por fim, a região Sul também aumenta sua especialização nas atividades desse grupo de indústria, mas ainda inferior ao padrão nacional; a produtividade média correspondente dos ramos dessa indústria manteve-se abaixo da média nacional e inferior ao valor observado nas regiões Norte, Nordeste e Sudeste. Para essa última região, o padrão setorial observado não corresponde exatamente ao esperado. Na verdade, é possível pensar que o adensamento industrial verificado nela privilegiaria os ramos de atividade de maior densidade técnica e com maior produtividade, o que não ocorreu.

No grupo de indústria com tecnologias diferenciadas como fator competitivo mais relevante, destacam-se com especializações superiores as regiões Sudeste e Sul e, de modo excepcional, a região Norte com sua produção concentrada na ZFM privilegiada por incentivos fiscais. Se se desconsidera, no entanto, os efeitos espúrios da produção na região Norte, é no Sudeste e no Sul que essas atividades são mais relevantes e até mesmo teriam produtividade acima da média nacional. As duas regiões responderam em 2015 por 91,4 \% do total nacional do grupo de indústria (Sudeste, 60,9 \% e Sul, 30,5 \%), conforme dados na própria tabela. As regiões de menor desenvolvimento relativo, Nordeste e Centro-Oeste, combinam rarefação de atividades nesse grupo com produtividade média também inferior à nacional.

Nas indústrias baseadas em ciência, a especialização é bastante evidente na região Norte e no Sudeste. A primeira produz 21,3\% do VTI do total nacional do grupo enquanto a segunda produz, no mesmo ano, $60,8 \%$. Os níveis de produtividade

6 A economia do estado do Amazonas detinha, em 2015, a parcela de 2,9 \% do VTI nacional do grupo de indústria de intensivos em trabalho; esse percentual corresponde, por sua vez, a 82,8 \% do total regional do grupo (dados da PIA-IBGE). 
associados também são mais elevados nessas regiões do que nas demais. Na região Norte, a tendência da razão de produtividade ao longo do período foi decrescente e no Sudeste ela manteve-se crescente. A região Sul aumentou sua participação nesse grupo de indústria com especialização e passou de $\mathrm{CE}=0,24$ em 1996 para $\mathrm{CE}=0,54$ em 2015; seus níveis médios de produtividade, contudo, mantiveram-se abaixo e em torno de $60 \%$ dos nacionais.

O essencial desta análise, em meio ao quadro de nuances variadas, deve ser registrado. As regiões mais desenvolvidas industrialmente, principalmente a região Sudeste, têm retido em seus territórios os ramos de atividade com maior densidade de tecnologia e de produtividade média (intensivas em escala, diferenciadas e baseadas em ciência). As regiões Norte, Nordeste e Centro-Oeste, por sua vez, têm avançado posições mais substanciais nas indústrias baseadas em recursos naturais e trabalho e têm tido sucesso em expandir algumas posições nas atividades intensivas em escala.

\section{CONCLUSÕES}

A investigação permitiu demonstrar que a distribuição regional das atividades industriais no Brasil continuou a se desconcentrar entre 1996 e 2015. Esse resultado não confirma preocupações recorrentes de pesquisadores sobre o retorno à concentração industrial no país em função do quadro mais adverso da inserção internacional da economia brasileira. Contudo, ainda permanecem outras importantes razões para inquietações relacionadas com o contexto constatado de regressão da estrutura industrial.

O ajustamento da indústria brasileira caracterizou-se pela prevalência de reduzidas taxas de crescimento do VTI total; de redução da produtividade média real das atividades industriais - exceto do grupo de baseados em recursos naturais, e de aumento da participação relativa das atividades intensivas em recursos naturais no total da indústria, as quais passaram de $34,5 \%$ para $49,5 \%$ do total entre 1996 e 2015.

Ademais, os níveis gerais de concentração da atividade industrial permanecem elevados, em que pese a queda verificada. As regiões mais desenvolvidas ainda retêm as atividades industriais mais relevantes e de produtividade mais elevada. Apenas se deslocaram para as regiões menos industriais as atividades ligadas aos diferenciais de dotação de fatores de recursos naturais e mão de obra nos quais elas são mais competitivas. 


\section{REFERÊNCIAS BIBLIOGRÁFICAS}

Arend, Marcelo; Singh, Guilherme e Bicharra, Julimar (2016). Mudança Estrutural Redutora da Produtividade: o falling behind brasileiro. Em: 44 Encontro Nacional de Economia-ANPEC.

Borbély, Dora (2004). Competition among Cohesion and Accession Countries: Comparative Analysis of Specialization within the EU Market. European Institute for International Economic Relations. Em: University of Wuppertal. Discussion Paper n. ${ }^{\circ} 122$, p. 1-41.

Bourguignon, François (1979). Decomposable Income Inequality Measures. Em: Econometrica, vol. 47, n. ${ }^{\circ}$, p. po1-920.

Cano, Wilson (2012). A desindustrialização no Brasil. Em: Revista Economia e Sociedade, Campinas, vol. 21, Número Especial, p. 831-851.

Cano, Wilson (1998). Desequilíbrios regionais e concentração industrial no Brasil, 1930-1970 e 1970-1995. Campinas: Editora Unicamp, 382p.

Diniz, Clécio C. (1995). A dinâmica regional recente da economia brasileira e suas perspectivas. Texto para Discussão, n. ${ }^{0}$ 375. Ipea: Brasília, p. 1-38.

Diniz, Clélio C.; Crocco, Marco Aurélio (1996). Reestruturação Econômica e Impacto Regional: o novo mapa da indústria brasileira. Em: Nova Economia, vol. 6, n. ${ }^{\circ}$ 1, p. 77-103.

Galeano, Edileuza; Feijó, Carmen (2013). A estagnação da produtividade do trabalho na indústria brasileira nos anos 1996-2007: análise nacional, regional e setorial. Em: Nova Economia, vol. 1, n. ${ }^{\circ} 23$, p. 9-50.

Haddad, Paulo; Ferreira, C. M. C.; Boiser, S. e Andrade, T. A. (1989). Economia regional: teorias e métodos de análise. Fortaleza: Banco do Nordeste, 649p.

Nassif, André (2008). Há Evidências de Desindustrialização no Brasil? Revista de Economia Política, vol. 28, n. ${ }^{\circ}$ 1, p. 72-96.

Negri, Barjas (1996). Concentração e desconcentração industrial em São Paulo (1980-1990). Campinas: Editora Unicamp, 242p.

OECD — Organization for Economic Cooperation and Development- (1987). Structural Adjustment and Economic Performance. Paris: OECD, 371p.

Pacheco, Carlos Américo (1998). Fragmentação da Nação. Campinas: Editora Unicamp, 290p.

Pimes —Programa Integrado de Mestrado em Economia e Sociologia- (1984). Desigualdades Regionais no Desenvolvimento Brasileiro. Recife: UFPE/IPEA/Sudene.

Ram, Rati (1992). Interstate Income Inequality in the United States: measurement, modelling and some characteristics. Review of Income and Wealth, vol. 7. n. ${ }^{\circ}$ 3, p. 485-549. 